\title{
Successive phase transitions and dual dielectric switching in an organic-inorganic hybrid perovskite
}

Lin Zhou, ${ }^{1,2}$ Rui-Xia Li ${ }^{1}$ Ping-Ping Shi, ${ }^{1}$ Qiong $Y e^{1, *}$ and Da-Wei Fu ${ }^{1, *}$

${ }^{1}$ Ordered Matter Science Research Center, and Jiangsu Key Laboratory for Science and Applications of Molecular Ferroelectrics, Southeast University, Nanjing 211189, P. R. China.

${ }^{2}$ College of Chemistry, Nanchang University, Nanchang 330031, P. R. China

E-mail: yeqiong@seu.edu.cn; dawei@seu.edu.cn 


\section{Experimental section}

X-ray Crystallography and PXRD. Variable-temperature X-ray diffraction data of compound 1 were collected on a Rigaku Varimax ${ }^{\mathrm{TM}}$ DW diffractometer with $\mathrm{Cu} \mathrm{K} \alpha$ radiation $(\lambda=1.54184 \AA$ ) (data collected at $360 \mathrm{~K}$ using Mo $\mathrm{K} \alpha$ radiation, $\lambda=0.71073$ $\AA$ ). The Hypix-6000HE detector and program CrysAlisPro (Rigaku OD, 2019) were used for collection of diffraction data and data processing including empirical absorption corrections, respectively. The crystal structures were solved by direct methods and refined by full-matrix least-squares refinements on $F^{2}$ using the SHELXLTL software package. All nonhydrogen atoms were refined anisotropically and the positions of all hydrogen atoms were generated geometrically. The asymmetric units and the packing views were drawn with DIAMOND Visual Crystal Structure Information System Software. Crystallographic data and structure refinement are listed in Table S1. PXRD data for compound $\mathbf{1}$ was measured on a Rigaku Varimax ${ }^{\mathrm{TM}} \mathrm{DW}$ diffractometer using $\mathrm{Cu} \mathrm{K} \alpha$ radiation and collected in the $2 \theta$ range of $5^{\circ}-50^{\circ}$ with a step size of $0.01^{\circ}$ from 295 to $373 \mathrm{~K}$.

DSC, TGA and Raman Measurements. DSC measurement was performed on powder sample of compound 1 by a NETZSCH DSC 214 Polyma instrument in the temperature range of $173-418 \mathrm{~K}$ with a heating/cooling rate of $10 \mathrm{~K} / \mathrm{min}$. The sample was placed in aluminum crucible under nitrogen at atmospheric pressure. Thermogravimetric analysis (TGA) was performed on a Netzsch Model TG 209 F3 instrument at a heating rate of $10 \mathrm{~K} / \mathrm{min}$ in nitrogen flow. Raman spectra were 
recorded in the temperature range of 323-363 K by using a WITec Alpha 300R Confocal Raman system with $532 \mathrm{~nm}$ excitation.

Dielectric Constant Measurements. The powder-pressed pellet of compound 1 pasted with carbon or silver conducting glue was used in dielectric measurements. The temperature-dependent dielectric constant was measured on a Tonghui Model TH2828A impedance analyzer within 203-358 $\mathrm{K}$ under the frequencies of $5 \mathrm{kHz}, 10$ $\mathrm{kHz}, 100 \mathrm{kHz}$ and $1 \mathrm{MHz}$, with the applied AC field fixed at $1 \mathrm{~V}$.

Optical Measurements. The ferroelastic domain structures in thin film of 1 were observed directly under an Olympus BX51TRF optical polarization microscope within 303-353 K. The samples were placed on the INSTEC HCC602 heating/cooling stage. Thin film of $\mathbf{1}$ was fabricated by the drop-casting method. An aqueous saturated solution ( $80 \mu \mathrm{L}$ ) of 1 was spread onto a prepared indium tin oxide (ITO)-coated glass, and a thin film was obtained by the in situ growth after annealing the film-coated substrate on a hotplate at $353 \mathrm{~K}$ for $10 \mathrm{~min}$. 
Table S1 Crystal data, data collection and reduction parameter of crystals of $\mathbf{1}$ at 193 $\mathrm{K}, 273 \mathrm{~K}, 338 \mathrm{~K}$ and $360 \mathrm{~K}$.

\begin{tabular}{|c|c|c|c|c|}
\hline Phase & LTP & RTP & ITP & НTP \\
\hline $\begin{array}{l}\text { Chemical } \\
\text { Formula }\end{array}$ & $\mathrm{C}_{11} \mathrm{H}_{18} \mathrm{CdN}_{3} \mathrm{PS}_{3}$ & $\mathrm{C}_{11} \mathrm{H}_{18} \mathrm{CdN}_{3} \mathrm{PS}_{3}$ & $\mathrm{C}_{11} \mathrm{H}_{18} \mathrm{CdN}_{3} \mathrm{PS}_{3}$ & $\mathrm{C}_{11} \mathrm{H}_{18} \mathrm{CdN}_{3} \mathrm{PS}_{3}$ \\
\hline Formula weight & 431.835 & 431.835 & 431.835 & 431.835 \\
\hline Temperature (K) & 193 & 273 & 338 & 360 \\
\hline Crystal system & Monoclinic & Monoclinic & Orthorhombic & Hexagonal \\
\hline Space group & $P 2_{1} / c$ & $P 2_{1} / c$ & $\mathrm{Cmcm}$ & $P 6_{3} / m m c$ \\
\hline$a, \AA$ & $16.3971(1)$ & $16.7888(1)$ & $9.7695(2)$ & $9.9390(6)$ \\
\hline$b, \AA$ & $10.7769(1)$ & $10.8048(1)$ & 17.1919(4) & $9.9390(6)$ \\
\hline$c, \AA$ & $19.6760(1)$ & $19.6319(1)$ & $10.8212(2)$ & $10.7883(6)$ \\
\hline$\alpha, \operatorname{deg}$ & 90 & 90 & 90 & 90 \\
\hline$\beta, \operatorname{deg}$ & $90.491(1)$ & $90.873(1)$ & 90 & 90 \\
\hline$\gamma, \operatorname{deg}$ & 90 & 90 & 90 & 120 \\
\hline$V, \AA^{3}$ & $3476.82(4)$ & $3560.81(4)$ & $1817.49(7)$ & 922.93(9) \\
\hline \multirow[t]{2}{*}{$\mathrm{Z}$} & 8 & 8 & 4 & 2 \\
\hline & $-20 \leq h \leq 20$ & $-21 \leq h \leq 21$ & $-12 \leq h \leq 12$ & $-13 \leq h \leq 13$ \\
\hline \multirow[t]{2}{*}{ Index ranges } & $-8 \leq k \leq 13$ & $-8 \leq k \leq 13$ & $-21 \leq k \leq 20$ & $-12 \leq k \leq 13$ \\
\hline & $-24 \leq l \leq 24$ & $-23 \leq l \leq 24$ & $-13 \leq l \leq 7$ & $-14 \leq l \leq 14$ \\
\hline$D_{\text {calcd }}, \mathrm{g} \cdot \mathrm{cm}^{-3}$ & 1.650 & 1.611 & 1.578 & 1.554 \\
\hline$\mu, \mathrm{mm}^{-1}$ & 14.222 & 13.887 & 13.443 & 1.597 \\
\hline refns measured & 24608 & 23735 & 5038 & 24940 \\
\hline $\begin{array}{l}\text { independent } \\
\text { reflns }\end{array}$ & 7287 & 7455 & 1059 & 545 \\
\hline reflns used & 6735 & 6707 & 868 & 201 \\
\hline $\begin{array}{l}\text { Goodness-of-fit } \\
\text { on } F^{2}\end{array}$ & 1.025 & 1.049 & 2.684 & 1.099 \\
\hline $\begin{array}{l}\text { Final } R \text { indices } \\
{[I>2 \operatorname{sigma}(I)]}\end{array}$ & $\begin{array}{l}R_{1}=0.0612 \\
w R_{2}=0.1654\end{array}$ & $\begin{array}{l}R_{1}=0.0688, \\
w R_{2}=0.2115\end{array}$ & $\begin{array}{l}R_{1}=0.2122 \\
w R_{2}=0.5772\end{array}$ & $\begin{array}{l}R_{1}=0.0679 \\
w R_{2}=0.2472\end{array}$ \\
\hline
\end{tabular}




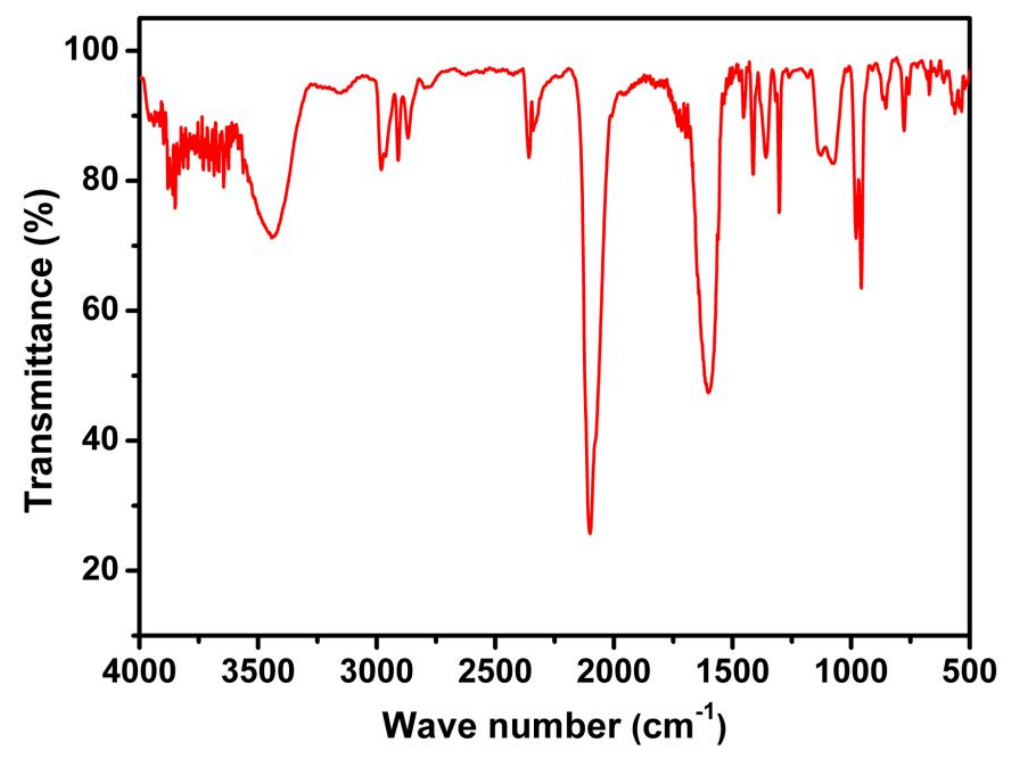

Figure S1. IR spectrum of 1 (measured on a Shimadzu Model IR-60 spectrometer), where the signal at $3500 \mathrm{~cm}^{-1}$ is due to the moisture of the $\mathrm{KBr}$ used for IR.

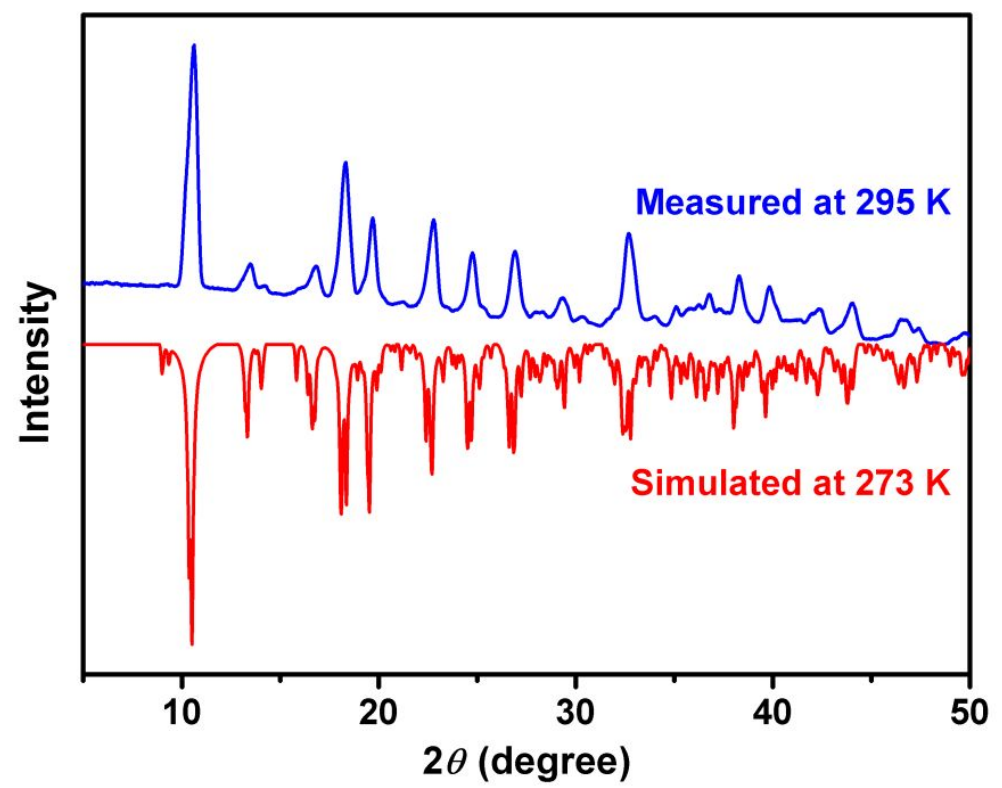

Figure S2. The experimental PXRD pattern of 1 obtained at room temperature, and simulated one based on the single crystal structure in RTP. 


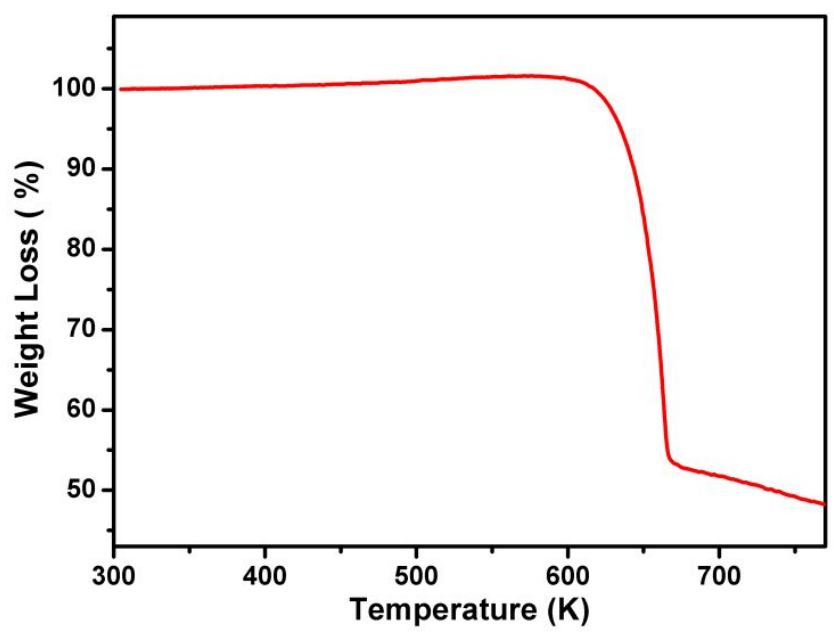

Figure S3. TGA curve of $\mathbf{1}$.

(a)

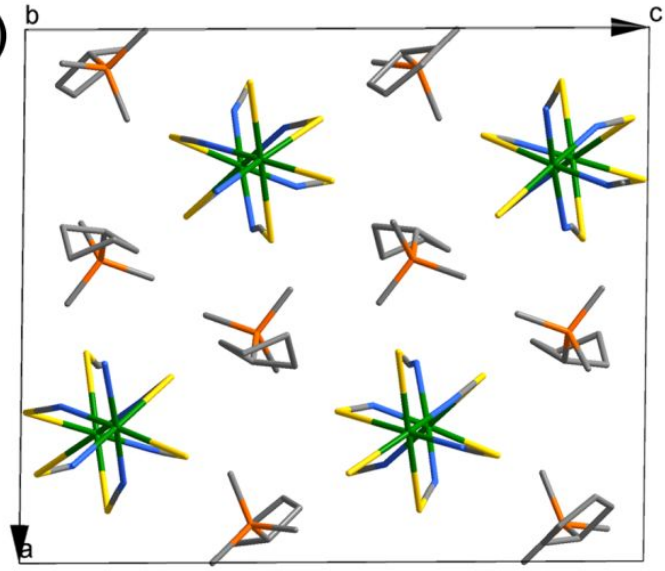

(b)

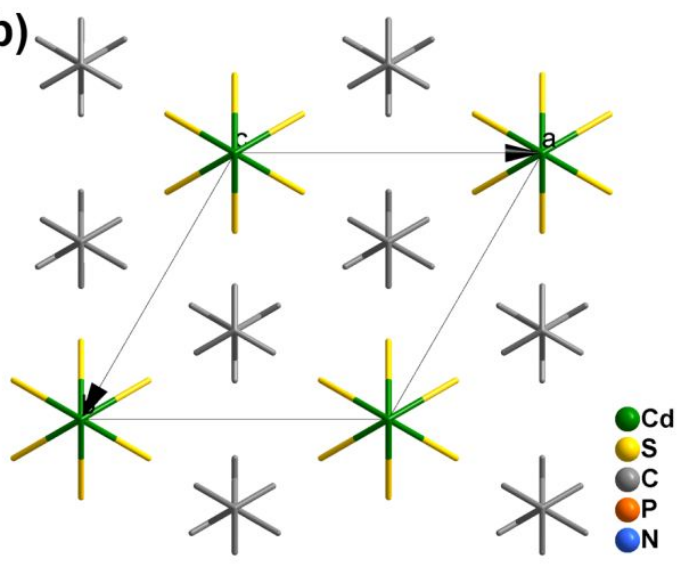

Figure S4. (a) Packing view of 1 in RTP along the $b$-axis. (b) Packing view of $\mathbf{1}$ in HTP along the $c$-axis.
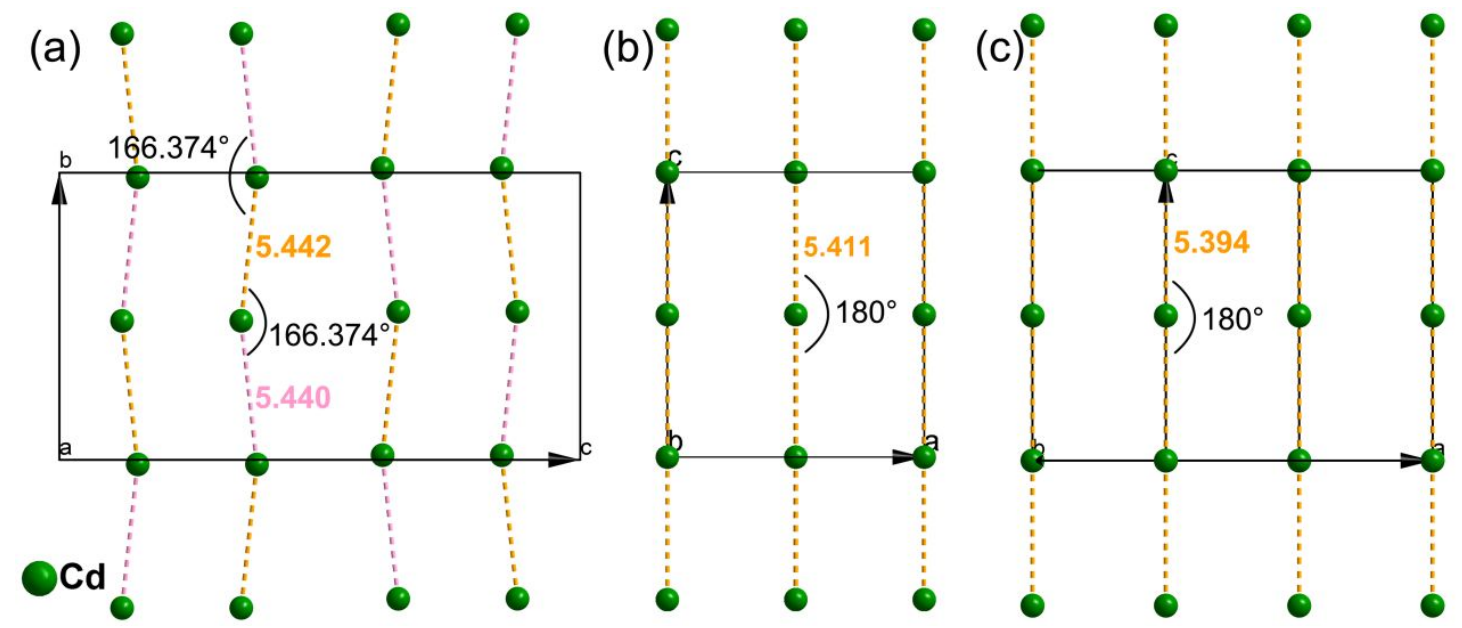

Figure S5. The $\mathrm{Cd} \cdots \mathrm{Cd} \cdots \mathrm{Cd}$ anionic chains in RTP (a), ITP (b) and HTP (c). 

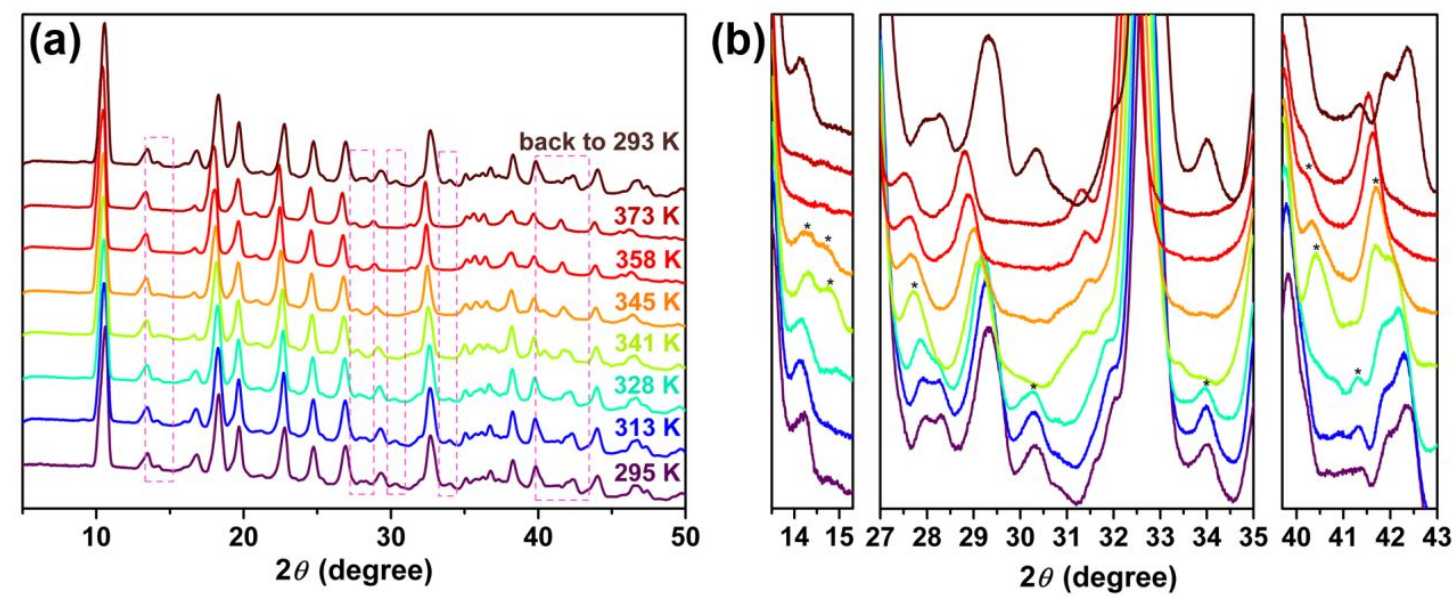

Figure S6. Variable-temperature PXRD patterns of 1 (a) within the $2 \theta$ range of 5-50',

(b) within some local ranges where the obvious changes occur.

The PXRD patterns recorded within $295 \mathrm{~K}$ to $373 \mathrm{~K}$ upon heating are depicted in Figure S6. On the whole, most of diffraction peaks show slight shifts to low $2 \theta$ angles with increasing temperature, but otherwise there is no significant change for the main peaks. However, by comparing small peaks, obvious differences can be observed in different phases. As shown in Figure S6b, the PXRD patterns recorded at 313 and 328 $\mathrm{K}$ match well with that recorded at $295 \mathrm{~K}$, corresponding to the RTP. When the temperature increases to $341 \mathrm{~K}$ (ITP), the diffraction peaks at $30.3^{\circ}, 34^{\circ}$ and $41.3^{\circ}$ disappear and new diffraction peaks emerge at $14.7^{\circ}$ and $40.4^{\circ}$ compared with the PXRD pattern in the RTP. Meanwhile, the peaks at $28^{\circ}$ and $28.3^{\circ}$ in the RTP seem to merge into one peak at $27.7^{\circ}$ in the ITP. And similar phenomenon also occurs for peaks at $42^{\circ}$ and $42.3^{\circ}$ at $345 \mathrm{~K}$. When the temperature continuously increases to 358 $\mathrm{K}$ (HTP), in comparison with the PXRD pattern at ITP, the diffraction peaks at $14.2^{\circ}$ and $14.7^{\circ}$ vanish and the peak near $40.4^{\circ}$ becomes less obvious in the HTP. Those changes in the PXRD patterns clearly indicate the occurrence of two phase transitions in the measured temperature range. After heating to $373 \mathrm{~K}$ and then cooling to room temperature, the PXRD pattern obtained at $293 \mathrm{~K}$ matches well with the initial PXRD pattern obtained at $295 \mathrm{~K}$, demonstrating that the two phase transitions are reversible. 


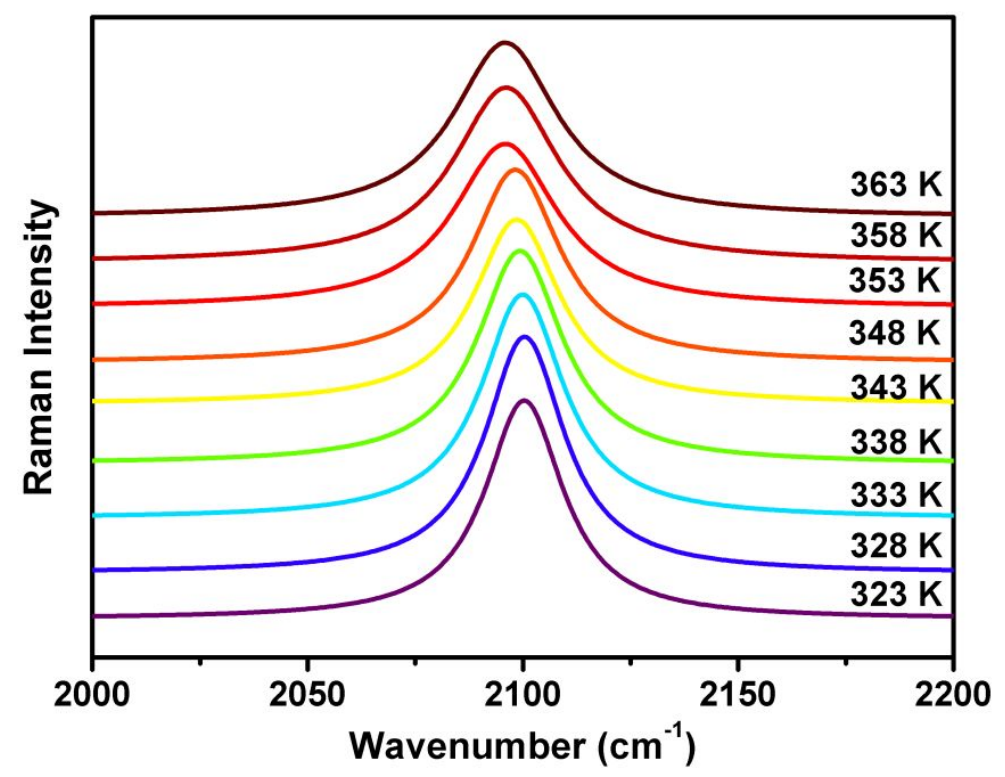

Figure S7. Raman spectra of $\mathbf{1}$ at various temperatures in the spectral range of $\sim 2100$ $\mathrm{cm}^{-1}$.
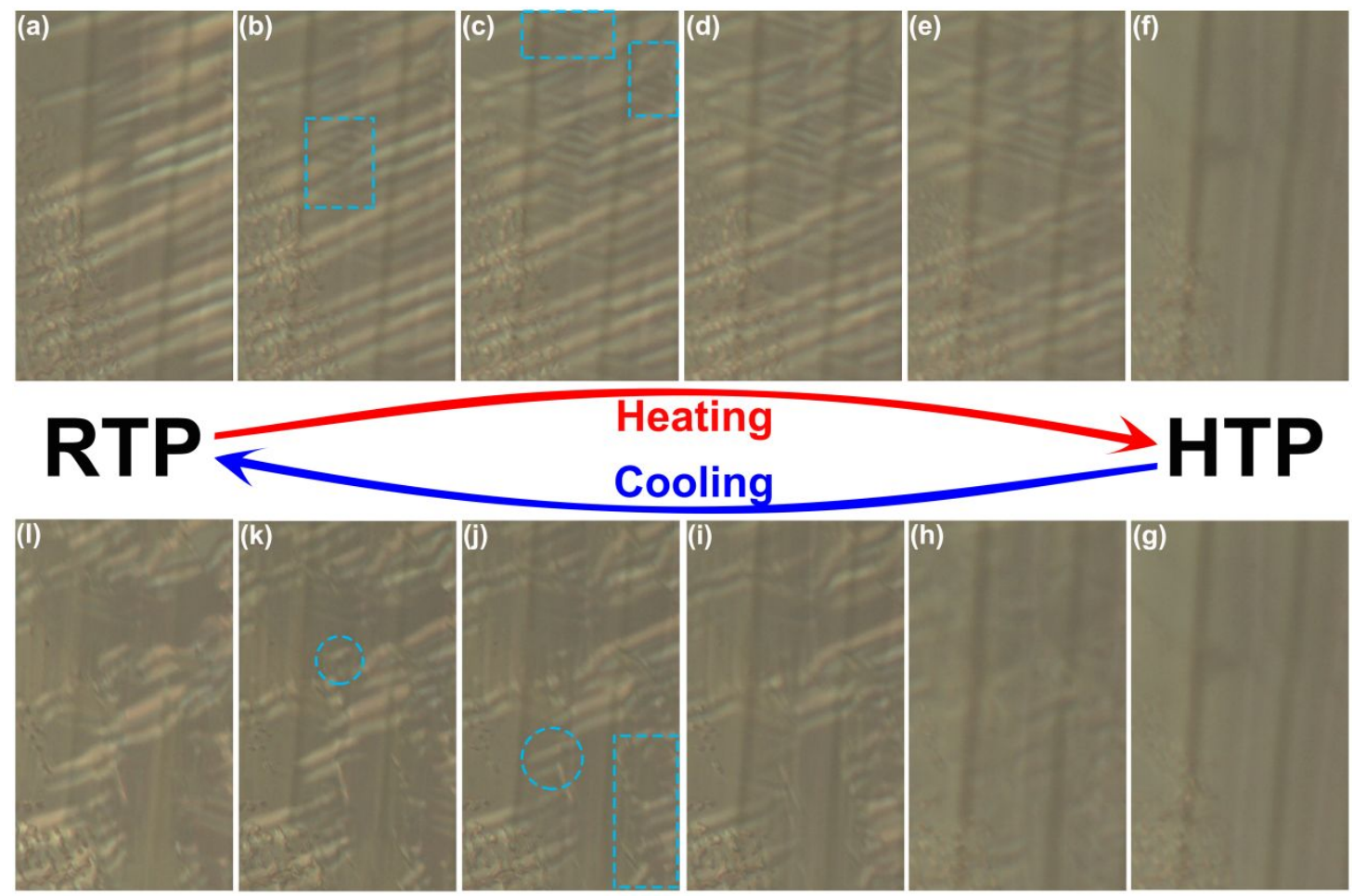

Figure S8. Evolution of the domain structure of $\mathbf{1}$ on the same area of the thin film in a heating (from (a) to (f)) and cooling (from (g) to (l)) process. The areas with significant changes are marked with blue dashed boxes. 

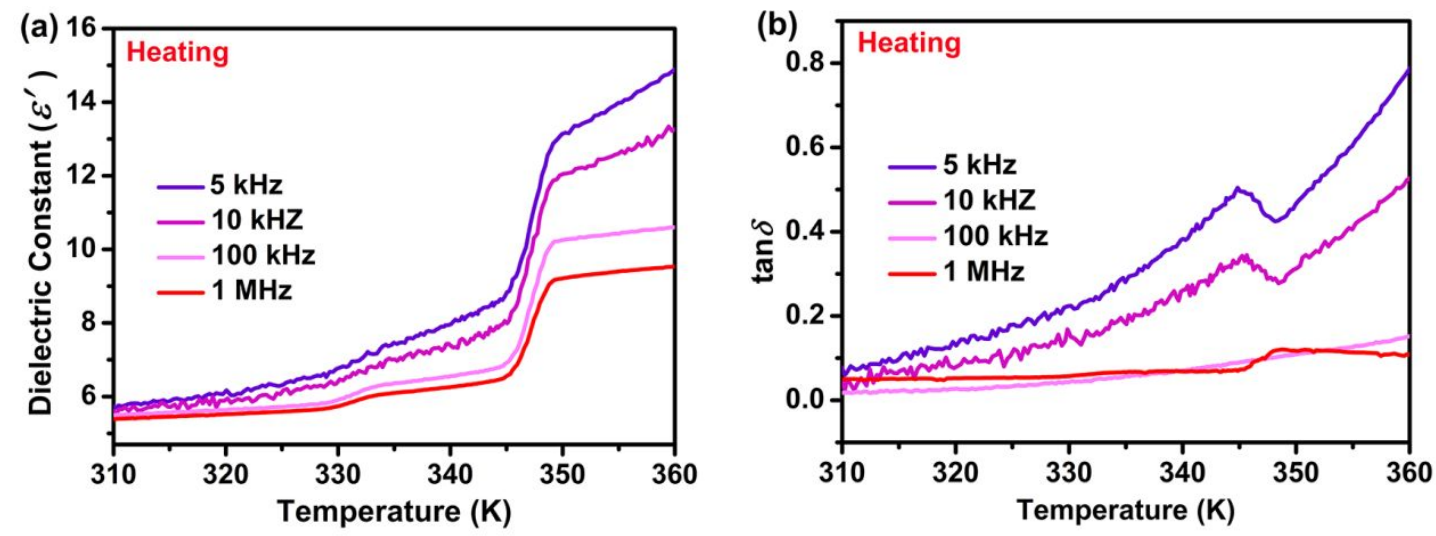

Figure S9. The dielectric constant $\left(\varepsilon^{\prime}\right)$ and dielectric loss $(\tan \delta)$ of 1 at different frequencies in the heating process.
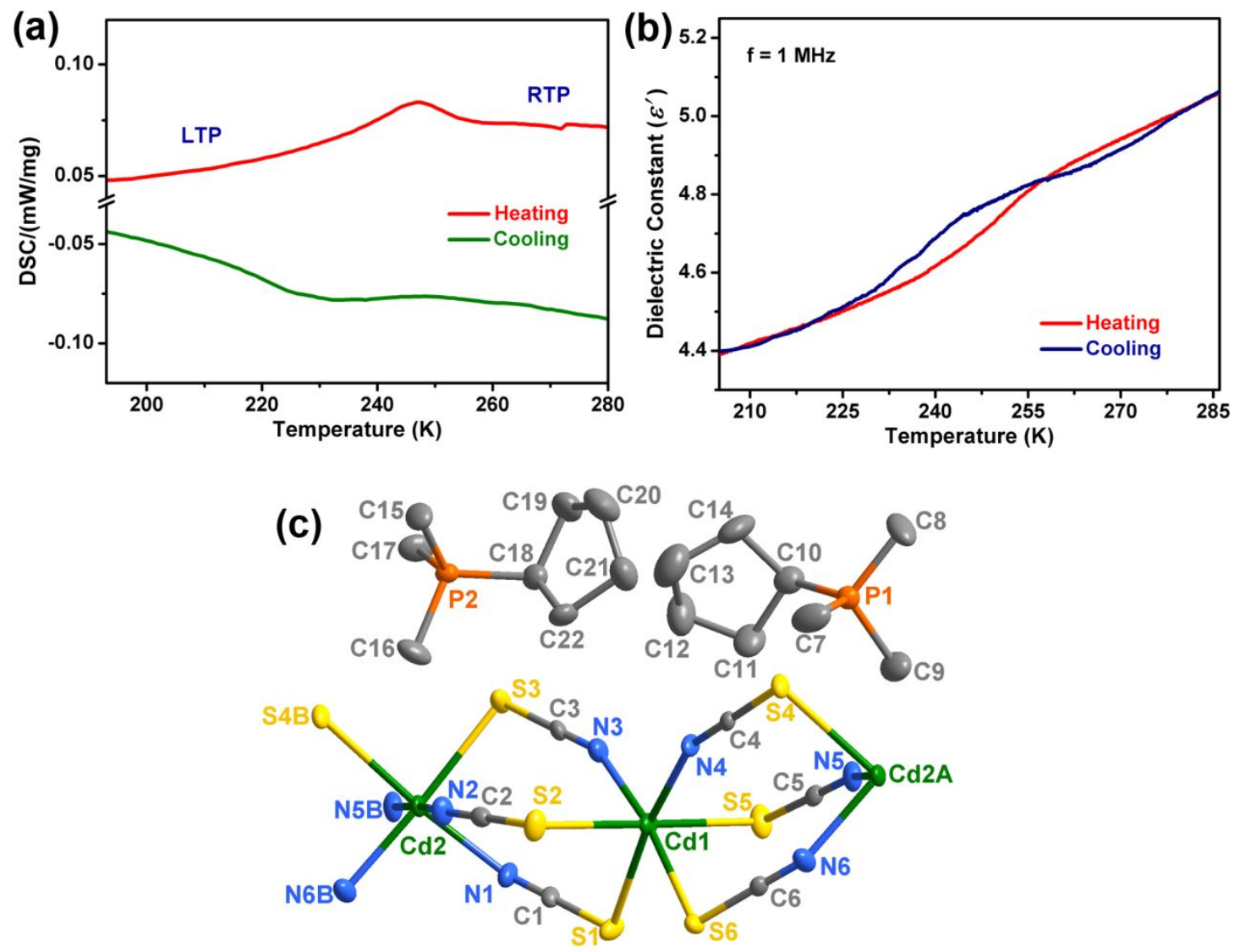

Figure S10. DSC curves (a) and dielectric constant $\left(\varepsilon^{\prime}\right)$ (b) of 1 below room temperature. (c) The asymmetric unit of 1 in the LTP with a $50 \%$ ellipsoid probability level. 